\section{Os museus etnográficos, os povos indígenas e a antropologia: reflexões sobre a trajetória de um campo de relações ${ }^{1}$}

\author{
Luís Donisete Benzi Grupioni²
}

Neste texto apresento algumas reflexões sobre a configuração de um campo particular de relações: aquele que se estabelece entre museus etnográficos, antropólogos e povos indígenas ao longo do século $\mathrm{XX}$ até os dias atuais no Brasil. Interessa por em evidência o sentido da formação, da guarda, do estudo e do uso de coleções etnográficas em museus e entender, de um lado, o papel destas coleções no desenvolvimento da etnologia brasileira, com vistas à compreensão do modo pelo qual este campo de relações se configura, se transforma e se amplia no Brasil, $\mathrm{e}$, de outro, analisar o protagonismo indígena recente em relação a esses acervos e a suas instituições guardiãs, com a entrada em cena de novos atores e instituições, quando novos tipos de produção cultural indígena - e de discursos indígenas acerca da própria cultura - tornam-se possíveis.

A trajetória deste campo é marcada por um processo em que as relações entre museus, antropólogos e povos indígenas se transformam significativamente ao longo do século $\mathrm{XX}$, em decorrência, tanto de alterações no estatuto das coleções etnográficas para a etnologia, quanto das mudanças de perspectiva em relação ao destino dos povos indígenas no Brasil, não apenas em termos demográficos, mas também políticos, na medida em que, inseridos num contexto radicalmente ampliado, hoje os povos indígenas são instados, em diferentes situações, a afirmar suas identidades. Com efeito, no início do século $\mathrm{XX}$, o esforço em recolher elementos da

1 Trabalho apresentado na Mesa 1: História dos museus na interface com a antropologia.

2 Doutorando em Antropologia no Programa de Pós-Graduação em Antropologia Social da Universidade de São Paulo e pesquisador do Iepé - Instituto de Pesquisa e Formação em Educação Indígena. E-mail: grupioni@ usp.br. produção material de pequenas sociedades que corriam o risco de se extinguirem, revela uma estreita ligação entre etnólogos e museus e um entusiasmo com relação ao potencial de pesquisa das coleções etnográficas, aliado a uma posição marginal dos índios neste campo de relações, figurando como meros informantes e produtores de artefatos. No período atual verifica-se um novo contexto em que a antropologia se faz longe dos museus, em que a prática da formação de coleções não está mais no cerne do fazer etnográfico, e em que a demanda em torno das coleções etnográficas depositadas em museus provém dos próprios povos indígenas interessados em estabelecer novos padrões de relacionamento com os pesquisadores e com as instituições que guardam testemunhos da produção material de seus antepassados. Trata-se, assim, de buscar aqui esboçar uma reflexão sobre a dinâmica de transformação de um conjunto de relações entre museus, povos indígenas e a antropologia no Brasil ${ }^{3}$.

\section{Trajetória de um campo de relações}

A formação de coleções de objetos é provavelmente quase tão antiga quanto a própria reflexão do homem sobre si mesmo. Recolher objetos e coisas, aqui e ali, afirmam museólogos e historiadores, é como "recolher pedaços de um mundo que se quer compreender e do qual

3 Incorporo neste artigo algumas reflexões apresentadas em minha dissertação de mestrado (1996) e depois publicadas em Grupioni (1998) para a parte mais histórica desse campo de relações, como ponto de partida para uma proposta de reflexão, em curso, que pretende inventariar as experiências contemporâneas entre índios $e$ museus no Brasil. 
se quer fazer parte ou então dominar" (Suano, 1986:12). Formada por evidências materiais de alguma atividade humana ou por elementos recolhidos da natureza, coleções de objetos sempre suscitam curiosidade, causam estranheza ou impelem a pôr algum tipo de ordem e classificação. Enfim, provocam reflexão.

É, sem dúvida alguma, longa a história do colecionismo no mundo, havendo registros do tempo das casas das musas gregas e das coleções particulares dos faraós egípicios, dos tesouros acumulados pela igreja e das coleções principescas, dos gabinetes de curiosidades e dos primeiros museus públicos. O próprio surgimento da antropologia muito tem a ver com a tarefa de ordenar coleções e refletir sobre elas. O estudo e a formação de coleções etnográficas sempre estiveram no horizonte de preocupações desta ciência. Vários autores já afirmaram que, em suas origens, a antropologia esteve associada aos museus e à constituição de grandes coleções, que forneceram as bases para a produção de modelos teóricos ou para sua ilustração. Nos últimos cem anos, os estudos daquilo que se convencionou chamar "cultura material" conheceram momentos de florescimento, desenvolvimento, estagnação e marginalização teórica e metodológica que, no seu conjunto, permitem mesmo escrever a história da disciplina, diferenciando escolas, linhas teóricas, autores e instituições.

Uma equação particular -artefatos/coleções/exposições - se impôs ao longo do tempo, adquirindo sentidos diversos entre diferentes gerações de pesquisadores e nos vários museus etnográficos aos quais historicamente foram confiadas as funções de guarda, preservação, estudo e divulgação de acervos materiais.

Buscar esses sentidos pode nos conduzir a uma melhor compreensão de algumas das causas que explicam a crise que hoje se abate sobre os museus etnográficos no Brasil, tornando-os, na linguagem do senso comum, "locais onde se depositam coisas velhas" distanciados da produção etnológica recente e dos dilemas enfrentados pelos povos indígenas no presente.

Um caminho possível para isto pode ser o da reflexão do por quê desta equação artefatos/ coleções/exposições não se realizar de fato, e o de buscar alternativas e novas perspectivas, que justifiquem, de modo objetivo e ético, o esforço de conservação de artefatos etnográficos de povos indígenas em museus brasileiros, restituindo a lógica de algo que teve um começo e que pode ter um fim útil, não só para a antropologia como ciência, mas para os povos que ela busca compreender.

\section{Os museus etnográficos e a coleta de artefatos}

$\mathrm{O}$ processo de institucionalização da antropologia no Brasil e o papel desempenhado pelos museus etnográficos nessa história não é de todo diverso do que ocorreu em outros países, sendo, em certos aspectos, conseqüência mesmo dos processos em curso nestes outros centros. Foram os museus etnográficos, notadamente o Museu Nacional, no Rio de Janeiro, o Museu Paulista, em São Paulo, e o Museu Goeldi, no Pará, que abrigaram as primeiras pesquisas científicas sobre as sociedades indígenas no Brasil, recebendo e respaldando pesquisadores estrangeiros, promovendo expedições de pesquisa, incorporando as coleções de artefatos recolhidas, junto a estes povos, por pesquisadores estrangeiros e nacionais e publicando os primeiros trabalhos e monografias etnográficas. As expedições científicas empreendidas no início deste século, com o intuito de coletar material etnográfico destinado à formação de coleções, caracterizavam-se pelo espírito de aventura que as cercavam: desbravar territórios ainda virgens ou pouco explorados e ir ao encontro de populações nativas desconhecidas. Revestiam-se, também, de um caráter humanista: era preciso preservar a cultura dos povos indígenas que fatalmente iriam se extingüir, daí a significação ganha, neste período, pelo recolhimento de artefatos por eles produzidos. As coleções etnográficas cumpriam, assim, um papel fundamental: como documentos materiais das mais diversas formas da atividade humana, elas se constituíam no registro palpável da diferença e, antes que essa desaparecesse, era fundamental aprisioná- 
la, para que ela fosse preservada, estudada e exibida.

A formação de coleções etnográficas, botânicas, mineralógicas e outras foi o produto mais evidente das expedições de caráter científico desenvolvidas no início do século passado no Brasil. Com efeito, desde o século passado, a coleta e o comércio de artefatos etnográficos era corrente e vários museus estavam envolvidos em transações de coleções da África, da Ásia, Oceania e América, levadas por viajantes, agentes coloniais e pesquisadores. Enquanto a não especialização é o que marca o surgimento de tais museus, alguns deles foram fundados para a guarda de coleções principescas ou formados enquanto gabinetes de curiosidades; é a criação de departamentos específicos, que permitia a organização de peças de diversas proveniências, o que caracteriza seu desenvolvimento. O Brasil não foi exceção, ao contrário, fazia parte da rota de viajantes e pesquisadores e estava no rol de interesse de museus estrangeiros.

O Brasil figurou com destaque entre os provedores de peças etnográficas, principalmente em relação aos museus alemães ${ }^{4}$ Ainda que o colecionismo fosse uma prática de vários países europeus, deve-se reconhecer que foi na tradição histórico-cultural germânica que a atividade museográfica ganhou proporções inigualáveis. É justamente esta a tradição que se fez mais presente no Brasil. Tal presença se deu, tanto de forma direta, com a vinda de viajantes e pesquisadores alemães, quanto de forma indireta, via a produção antropológica norte-americana, fortemente ancorada no difusionismo e no determinismo geográfico herdados da tradição germânica.

Além de compras e financiamento de expedições, os museus aumentavam seus acervos lançando mão de permutas de peças e coleções, prática que, a julgar pela quantidade de peças que aparecem nos catálogos e livros de tombo com a rubrica permuta, mostra-se mui-

4 O Museu Etnológico de Berlim, por exemplo, fundado em 1873, financiou, entre outras expedições, as de Max Schmidt, Theodor Koch-Grunberg, Emil Heinrich Snethlage, Karl von den Steinen e Curt Nimuendajú, que resultaram num considerável acréscimo de peças provenientes de grupos indígenas no Brasil ao acervo da instituição. to recorrente no início deste século. A presença de certos pesquisadores nos cargos de direção dos museus, muitas vezes direcionaram os esforços de coleta para certas áreas de interesse, entre as quais figurava o Brasil. É o que parece sugerir Métraux (1935) com relação à influência de Nordenskiold sobre o Museu Etnográfico de Gotemburgo e sua predileção pelos povos da América do Sul. O mesmo podendo ser dito de outro americanista, Fritz Krause, do Museu de Etnologia de Leipzig, que foi o idealizador de um grande financiamento que permitiu ao etnólogo Curt Nimuendajú, realizar coletas durante os anos de 1928 e 1929 para três museus da Alemanha: o de Leipzig, Dresden e Hamburgo.

No Brasil, o mesmo movimento também pode ser percebido. Ao assumir a direção do Museu Paulista, von Ihering não só empreendeu várias expedições de coleta, como agenciou outros pesquisadores para tal fim, procurando aumentar o acervo daquele instituto. O Museu Goeldi, na gestão de Carlos Estevão de Oliveira, beneficiou-se em larga medida da ligação deste diretor com Curt Nimuendajú, que vendeu várias coleçōes para aquele museu. $\mathrm{O}$ mesmo vale para o Museu Nacional, embora este apresente a singularidade de ter sido o principal recebedor de empreendimentos oficiais, constando em seus livros de tombo desde coleções de artefatos de expedições apoiadas pelo Imperador até, em anos mais recentes, provenientes da Comissão Rondon e de funcionários do SPI. Os museus envolviam-se no financiamento de expedições para ampliar seus acervos através da incorporação de novas coleções.

Essas relações tão estreitas entre museus alemães e o Brasil são explicadas por Anne-Christine Taylor (1984) pelo fato de que, enquanto no século XIX, França e Inglaterra voltavam-se para suas colônias na África e na Ásia, construindo ali o berço da etnologia, a Alemanha, sem o mesmo poder colonial de seus vizinhos sobre as populações nativas de outros continentes, permanecia voltada para a América e influenciava a etnologia norte-americana com suas idéias culturalistas e difusionistas, bem como mantinha estreitos laços com o Brasil, promovendo pesquisas e adquirindo materiais etnográficos. Foi assim que se formou um triângulo de relações entre pesquisadores alemães, 
brasileiros e norte-americanos, cujo pano de fundo era dado pelo vínculo que mantinham com a tradição germânica.

Nesta linha de interpretação, o interesse da etnologia norte-americana pelo Brasil seria tributário desta influência germânica e responsável pela ampliação dos estudos consagrados às sociedades indígenas da América do Norte em direção à América do Sul, abrindo novos campos de investigação para os estudos, em voga na época, sobre migrações, trocas e contatos entre culturas. Estes desembocaram nos trabalhos sobre padrões culturais associados a determinadas áreas culturais.

Inicialmente organizado a partir de classificações lingüísticas e da configuração de regiões ecologicamente homogêneas, o critério das áreas culturais foi ampliado de modo a incluir outros conjuntos de traços que se constituíssem enquanto "provas" de uniformidades culturais, notadamente, de elementos materiais, como a cerâmica, o trançado e a tecelagem. Interessante observar que foram os acervos de artefatos etnográficos depositados em museus e os estudos de cultura material que forneceram as bases para se pensar os critérios para as áreas culturais. Entretanto, a necessidade de refinamento destes critérios acarretou um abandono dos próprios estudos de cultura material em favor de outras abordagens mais preocupadas com fatores relacionados à organização social, pois o principal obstáculo à aplicação do critério de áreas culturais às sociedades indígenas no Brasil residia justamente na falta de informações sobre um grande número destas sociedades.

Por outro lado, as coleções depositadas em museus e o início de pesquisas sistemáticas sobre determinadas sociedades indígenas acabaram levantando questões que possibilitaram o ingresso destas sociedades no debate etnológico internacional. Grupos com uma tecnologia simples, sem redes, cerâmicas, barcos e com uma agricultura incipiente, estavam sendo revelados como possuidores de complexos sistemas sociais e com uma elaborada vida cerimonial. As primeiras tentativas de explicação deste paradoxo, embasadas na assertiva de que a certos níveis de sucesso tecnológico corresponderiam certos níveis de sofisticação sociológica, mostravam-se insatisfatórias.
Foi o que ocorreu com os grupos indígenas do Brasil Central, considerados marginais e introduzidos no debate etnológico contemporâneo a partir deste paradoxo: tratava-se de grupos que apresentavam uma baixa especialização adaptativa e uma alta complexidade na estrutura social. A ampliação do conhecimento desta realidade só foi possível pela presença de pesquisadores norte-americanos que, juntamente com pesquisadores brasileiros, inauguraram uma nova fase na pesquisa etnológica no Brasil, centrada em trabalhos de campo intensivos, voltada para o debate antropológico que ocorria nos Estados Unidos, e preocupada, antes de tudo, com questões de estrutura e organização social.

Ao mesmo tempo observa-se profundas modificações nas instituições de pesquisa no Brasil. O estudo das coleções etnográficas mudava radicalmente de registro, na virada dos anos 60 , de um lado, com a transformação do caráter das expedições científicas, não mais voltadas para a coleta de artefatos, mas sim de dados sobre a organização social dos grupos indígenas, e, de outro, com a institucionalização das universidades brasileiras e a criação dos programas de pós-graduação. Estas obscureceram os museus e os institutos históricos, criando um novo padrão no conhecimento e na pesquisa científica no Brasil.

Naquele momento em que a pesquisa antropológica se transferia dos museus para a universidade, proliferaram os estudos monográficos, centrados em temas como mudança cultural, parentesco, mitologia e organização social (Cf. Corrêa, 1995 e Schwarcz, 1993). Em contrapartida, passa-se a registrar, a partir daquele período, um ingresso reduzido de novas coleções etnográficas nos museus brasileiros e uma estagnação nos estudos de cultura material. A formação de coleções torna-se secundária e seu estudo entra em derrocada com as influências do estruturalismo e do estudo dos fenômenos da vida social do ponto de vista simbólico.

$\mathrm{O}$ estudo das sociedades indígenas que, até então, estava sob a égide dos principais museus etnográficos brasileiros transfere-se definitivamente para os recém-criados programas de pós-graduação em algumas das principais universidades do país. A estagnação dos estudos de cultura material no Brasil, que caracteriza a pro- 
dução etnológica brasileira nas décadas de 60 e 70 , vai encenar uma reversão nos anos 80 , com trabalhos que demonstram a potencialidade destes estudos como uma via de acesso interessante e promissora para a compreensão das sociedades indígenas. Embora numericamente insignificantes, se comparados com trabalhos centrados em outros temas (como parentesco, organização social e cosmologia), os estudos de cultura material começaram a ganhar número, na medida em que vincularam os artefatos com as sociedades que os produziram, conjugando novas pesquisas de campo com acervos depositados em museus, e vinculando o estudo da cultura material a questões colocadas pela etno-história, etno-estética, organização social, representação visual e identidade étnica ${ }^{5}$. Mas, a grosso modo, trata-se de um crescimento efêmero, que acompanha uma certa atividade desenvolvida pelos museus etnográficos naquela década. Nos anos 90 , acentuase a crise destes museus, com falta de pessoal e de recursos financeiros e, com ela, nada de substantivo é produzido nesta área.

Paralelamente a esta estagnação nos estudos de cultura material, assiste-se hoje, e aqui entramos num novo momento deste campo de relações, os povos indígenas colocarem demandas novas aos antropólogos e aos museus, pela criação e comercialização de produtos culturais diversificados, como livros, CDs, vídeos e performances ancoradas em reproduções de festas e rituais, e por iniciativas de constituir centros culturais e casas de cultura em suas próprias aldeias. Novas demandas também têm surgido por parte de comunidades indígenas que, por meio de movimentos de reafirmação étnica, reivindicam acesso a bens produzidos por seus antepassados e guardados em museus. Enquanto museus indígenas, feitos pelos índios e para os índios, começam a requisitar assessorias e estudos sobre seus objetos antigos, nos museus etnográficos brasileiros pode-se contar nos dedos de uma só mão os etnólogos envolvidos com a curadoria de coleções ou com estudos de cultura material indígena. De modo que é possível prever que, se não for motivado por questões acadêmicas,

5 Refiro-me, aqui, aos trabalhos desenvolvidos por Thekla Hartmann, Sonia Ferraro Dorta. Berta Ribeiro, Lux Vidal, Heloisa Fenelón Costa. Lúcia van Velthen e Vilma Chiara. como aconteceu na virada do século, os estudos de cultura material e os objetos depositados em museus entrarão em pauta novamente, por questões políticas.

Mas antes de entrar nesta problemática, que me parece ter ganho importância nos últimos anos, e para a qual os museus etnográficos não se mostram preparados, gostaria de refletir sobre algumas das causas que levaram, e talvez ainda levem, à não exploração, em termos de pesquisa, dos acervos depositados nos museus.

\section{Os museus etnográficos e a pesquisa com cultura material}

É fato que nos últimos anos muitos antropólogos têm defendido a pesquisa de coleções etnográficas depositadas em museus (Hartmann, 1976; Clifford, 1988; Ribeiro e van Velthem, 1992; entre outros). Mas é notório que isto permanece mais em termos de promessa e expectativa, que em termos de realização. Muitos fatores concorrem para esta situação. Um deles já foi explicitado há pouco, relativo ao fato de que a antropologia, pode-se assim dizer, nasceu nos museus, mas amadureceu nas universidades. $\mathrm{E}$ seu amadurecimento ocorreu juntamente com a proliferação do trabalho de campo, rito de passagem, carregado de significados, que chega a produzir um certo estigma em relação àqueles que não o experimentaram ou praticaram (Cf. Cantwell e Rothschild, 1981).

Num país como o Brasil, onde hoje vivem mais de 210 povos indígenas diferentes, a maior parte delas desconhecida na literatura antropológica, o campo de pesquisa é ainda vasto. Há regiões sobre as quais nada se sabe, fato que leva as novas gerações de antropólogos a priorizarem grupos nunca ou pouco estudados. Neste contexto, estudar peças de museus não parece ser algo muito atraente diante da possibilidade, dada ao etnólogo, de se deslocar para uma área indígena, passar alguns meses em campo, convivendo com uma determinada população, aprendendo sua língua, vivendo o seu dia-a-dia, 
tentando compreender seu modo de vida e sua visão de mundo, e poder voltar para a academia, munido de informações e dados próprios com os quais pode propor uma interpretação do que viu, ouviu e refletiu sobre aquele povo. A compreensão da realidade etnográfica indígena é, sem dúvida alguma, para as novas gerações, muito mais atrativa que o trabalho com documentos, sejam eles históricos ou materiais, como as peças depositadas nos museus. Hoje, os museus etnográficos estão desvinculados da pesquisa de campo, e com isso, estão distantes dos etnólogos e dos grupos indígenas por eles estudados (Cf. Lurie, 1981).

Outro motivo que reforça essa distância das novas gerações de antropólogos em relação aos museus diz respeito ao fato de que as coleções não são utilizadas no ensino da antropologia, não sendo raro que um antropólogo complete sua formação sem nunca ter pisado num museu (Cf. Ribeiro, 1993). Agregue-se a isto o fato de que os museus etnográficos não são mais alimentados com novos conjuntos de artefatos que poderiam ser comparados aos que estão guardados em seus acervos.

E aqui chegamos a uma outra questão, relacionada à composição das coleções depositadas nos museus etnográficos. Em quase todos os museus encontramos conjuntos significativos de peças sem identificação sequer do coletor e da data da coleta e muitas vezes também do grupo étnico que as produziu. Uma parte considerável das coleções existentes em museus brasileiros constituem, na verdade, conjuntos de peças, coletadas de forma aleatória, fragmentada e desacompanhada de uma documentação básica, necessária para seu estudo.

Pesa ainda contra estas coleções, pouco ou pobremente documentadas, o fato de terem sido, em sua maioria, reunidas por coletores com interesses variados e com pouca ou nenhuma orientação teórica. Algumas são formadas por apenas um tipo de artefato, outras só por exemplares mais vistosos, de modo que retratam apenas parcialmente o universo material dos grupos representados. É o caso, para citar apenas um exemplo, da coleção formada por Raymundo Lopes, logo após a pacificação dos índios Urubu-Kaapor, em 1930. Ele depositou no Museu Nacional do Rio de Janeiro uma enor- me coleção constituída basicamente por flechas com pontas de metal, produzidas pelos índios a partir de facões, panelas e facas distribuídas na pacificação. Tamanha é a coleção de flechas, que provavelmente deixou os Urubu-Kaapor desarmados, o que juntamente com as epidemias que não tardaram a surgir, quase os levou à extinção (Cf. Ribeiro, 1977).

Se é certo que artefatos indígenas vêm sendo recolhidos desde 1500 , é verdade também que não há uma obra de referência que oriente o pesquisador sobre estes acervos, não se sabendo o que se tem, nem como se ter acesso a eles. Muitos museus possuem apenas seus livros de tombo, onde estão registrados o nome da coleção, a data de coleta ou de entrada no museu, e a relação das peças. De modo geral, não há informações sistematizadas sobre localização, proveniência, número, condições de coleta que permitam um rápido acesso ou seleção dos materiais. " $O$ interessado deve bater de porta em porta nessas instituições para verificar pessoalmente se armazenam materiais significativos para o trabalho a que se propõe" queixam-se Damy e Hartmann (1986).

Agregue-se a isto o fato de que boa parte das coleções está depositada em reservas técnicas, as peças separadas por categorias de matéria-prima, e não por grupos étnicos, o que se justifica pela natureza dos materiais empregados nos artefatos e pela falta de espaço, mas dificulta enormemente a pesquisa da produção material de uma sociedade específica. $O$ acesso não é direto e usualmente exige esforço e paciência para vencer os impasses burocráticos sempre apresentados aos pesquisadores interessados em conhecer acervos de peças dos grupos indígenas que estão estudando (Cf. Ribeiro, 1993).

Os museus etnográficos se ressentem hoje em dia da falta de pesquisadores qualificados voltados para o estudo, tanto das expressões materiais dos grupos indígenas, quanto dos acervos ali guardados. Ressentem-se também da crônica falta de verbas e da situação muitas vezes precária de suas reservas técnicas. Não há recursos ou motivação para aquisição de novas coleções, nem orientações para a coleta de peças, de forma que se formos verificar os acréscimos de novas coleções nos últimos anos, nestes museus, constataremos o ingresso de poucas peças e uma 
ou outra coleção. Alguns museus mantêm exposições permanentes, corroídas pelo tempo, com temáticas ultrapassadas, com artefatos que perderam a cor ou estão se desfazendo nas vitrines, diante dos olhares do público. Poucos museus possuem serviços educativos ou visitas guiadas e orientadas, de forma que alguns acabam por contribuir para a reprodução de estereótipos, manifestando um descuido generalizado com a atualização de informações sobre os povos indígenas, cujas expressões materiais estão expostas em suas vitrines.

De tudo isto se conclui que, quando muito, os museus estão cumprindo o papel de guardar artefatos, ainda que enfrentem cotidianamente enormes dificuldades para sua conservação, mas nem o seu estudo científico, nem a sua divulgação, estão, de modo geral, sendo levados a bom termo. Esta situação é tributária da forma como historicamente estas instituições foram constituídas.

\section{Os museus etnográficos e os povos indígenas}

Se as coleções, reunidas por antropólogos do passado, não apresentam, de modo geral, maior interesse aos antropólogos do presente, elas têm despertado, cada vez mais, o interesse dos seus criadores e herdeiros, refiro-me, aos próprios povos indígenas, para os quais estas coleções começam a ganhar novos e inusitados significados, evidenciando a reconfiguração deste campo de relações na atualidade.

E aí temos um primeiro ponto a ser levado em consideração no que diz respeito à trajetória deste campo de relações entre museus, etnólogos e povos indígenas: o da enorme distância entre estes povos e as instituições que abrigam acervos de seus antepassados, distância esta tributária do modo como, na primeira metade do século passado, os etnólogos se posicionaram dentro deste campo de relações, não priorizando uma interlocução com os produtores dos artefatos coletados enquanto sujeitos integrantes do processo. Fato é que, em grande medida, o colecionismo etnográfico esteve alimentado pela idéia do desaparecimento das culturas tribais, e este foi o mot que levou à realização de diversos e diferentes empreendimentos de coleta de materiais etnográficos em várias épocas e regiões do Brasil. Mas contra as previsões, muitos povos resistiram aos efeitos deletérios do contato e continuam a se perpetuar enquanto grupos étnicos diferenciados, portadores de tradições culturais próprias. Outros grupos, após passarem anos procurando esconder suas origens étnicas, reivindicam hoje o reconhecimento de suas identidades diferenciadas (Cf. Oliveira Filho, 1993).

Evidentemente, muitos grupos deixaram de existir enquanto totalidades sociológicas, mas os que sobreviveram, continuam afirmandose enquanto povos, e é para alguns deles que as coleções depositadas em museus começam a ganhar sentido, seja porque, expostas em museus e em exposições, revestem-se de uma importância que lhes permite sentir orgulho de suas produções materiais e de suas próprias identidades indígenas, comumente sujeitas a preconceitos e estigmas; seja porque, nestas produções, identificam matrizes culturais de práticas e valores que foram perdidas ou abandonadas ao longo do tempo, e para as quais lançam tentativas de recuperação e de resgate, em processos de reafirmação étnica.

Este é o contexto que dá um novo sentido para a existência de coleções etnográficas depositadas em museus e que cria novos desafios ainda não equacionados. Cabe investigar qual o sentido da preservação destas coleções, tanto para os povos indígenas, quanto para as instituições que, de longa data, as mantêm em seus acervos.

Comparadas com experiências em curso no Canadá, Estados Unidos, Nova Zelândia e México, as relações dos povos indígenas com os museus etnográficos, no Brasil, são ainda muito incipientes evidenciando uma distância muito grande entre os povos indígenas contemporâneos e os acervos de cultura material de seus antepassados, guardados nas reservas técnicas dos museus etnográficos (cf. Clifford, 1992). Para muitos museus é como se estes povos, dos quais tais instituições mantêm exemplares de suas expressões materiais, não existissem mais, ou como 
Museu, Identidades e Patrimônio Cultural.

Rev. do Museu de Arqueologia e Etnologia, São Paulo, Suplemento 7, 2008.

se o trabalho que realizam nada tenha a ver com a sua presença e a sua situação no presente.

Na contramão desta postura, hoje, vários povos indígenas estão descobrindo os museus e seus acervos e, neste contexto, novas demandas e novas possibilidades de comunicação podem surgir entre eles e os museus etnográficos. Esse interesse crescente, manifesto por vários povos indígenas, marca um novo contexto no campo de relações formado pelos museus etnográficos, pesquisadores e povos indígenas e aponta para novas possibilidades de relacionamento.

Em anos recentes, alguns povos indígenas estão se apropriando de instituições típicas da sociedade envolvente para reforçar laços internos e valorizar suas práticas culturais, criando novos espaços de comunicação interna e com um público maior. É o caso da constituição de centros culturais indígenas e de museus indígenas, idealizados, construídos e apropriados por estes povos, não como meras cópias de instituições ocidentais, mas de acordo com suas lógicas próprias e mecanismos específicos de controle e gestão. Alguns tiveram vida efêmera, mas esta brevidade indica antes uma total integração às práticas dos grupos que as efetivaram, do que sua inadequação. Os museus etnográficos podem desempenhar um papel importante junto a estes grupos, propiciando que índios façam estágios em suas instituições, aprendam técnicas de curadoria, exposição e serviços educativos. Uma experiência interessante neste sentido vem se desenvolvendo em torno do Museu Kuahi, recentemente inaugurado na cidade de Oiapoque, Amapá, contando com assessoria especializada de antropólogos da USP e do Museu Goeldi.

Uma outra possibilidade de articulação dos museus etnográficos com representantes de comunidades indígenas pode ser efetivada por meio da identificação de acervos etnográficos e de documentos existentes nestas instituições, disponibilizando-os para os grupos indígenas interessados. Hoje, vários povos têm manifestado interesse em resgatar informações sobre o seu passado por meio de fotografias, documentos e artefatos guardados em museus. $\mathrm{Al}$ guns grupos têm realizado visitas a museus $\mathrm{e}$ feito pedidos específicos neste sentido. Alguns anos atrás, lideranças Parintintin deslocaram-se para São Paulo e Rio de Janeiro com o intuito de conhecer documentos, fotografias e artefatos de seus antepassados, reunindo cópias de materiais que foram levados para sua aldeia. Mais recentemente, índios Umutina de Mato Grosso empreenderam viagem semelhante à cidade do Rio de Janeiro, reunindo materiais que foram utilizados para confecção de um livro para uso na escola da aldeia.

Este fenômeno recente parece apontar para a possibilidade de que a questão das coleções etnográficas depositadas nos museus brasileiros entre em pauta novamente através de um movimento dos próprios índios como sujeitos do processo e com demandas específicas, envolvidos em atividades de valorização cultural e reafirmação étnica.

Reivindicações de acesso a bens culturais depositados em museus fazem parte, hoje, do rol de demandas do movimento indígena internacional, e têm sido debatidas em fóruns globais como a ONU e a UNESCO, gerando, inclusive, legislação específica para tratar de pedidos de repatriamento de bens culturais. Tais questões também já entraram em pauta no Brasil. Na Conferência Indígena realizada pela Funai em 2006, que reuniu cerca de 1.000 representantes indígenas de todo o país, entrou na pauta de reivindicações o acesso e a devolução de documentos históricos e etnográficos guardados em museus para as comunidades indígenas. No documento final, duas propostas merecem ser destacadas, pois revelam novas demandas indígenas. Diz este documento: "que o governo faça gestão, junto aos museus, pesquisadores, universidades, religiosos, colecionadores particulares $e$ governos de outros países, para que seja feita a devolução de todos os artefatos arqueológicos que foram retirados das terras indígenas sem conhecimento e autorização dos povos e comunidades indigenas" e "que os museus, universidades, igrejas, organizações governamentais e não-governamentais, no Brasil e no exterior, garantam a recuperação, conservação, organização, divulgação, acesso $e$ retorno do patrimônio material e imaterial guardados nestas instituições aos respectivos donos e produtores" (Funai, 2006).

A inclusão destas demandas, no rol de reivindicações formuladas pelo movimen- 
to indígena brasileiro, indica a necessidade de despertar os atores que compõem o campo que estamos analisando para a necessidade de estabelecimento de novas formas de comunicação entre si, fazendo com que surjam novas práticas de colaboração, de diálogo e de troca entre as instituições, os pesquisadores e os índios, inclusive em termos da composição de novas coleções e da realização de estudos científicos.

\section{Protagonismo indígena e novos desafios}

A iniciativa de alguns povos indígenas em abrir seus próprios museus ou centros culturais vem mostrando, que o museu pode ser um espaço vivo, de resgate da memória e de orgulho e afirmação de suas identidades étnicas. Em que pese a distância que ainda hoje permanece entre os grupos indígenas e os museus etnográficos no Brasil, os índios estão descobrindo que os museus podem ser um espaço importante em suas lutas de auto-determinação, como nos mostrou Freire (1998). Neste sentido, não será de todo estranho, que, por iniciativa deles, tais museus se vejam compelidos a mudar, a reformar suas exposições, a justificar seus acervos, a entabular novas formas de relacionamento com os grupos indígenas dos quais mantêm exemplares de suas expressões estéticas, simbólicas e materiais. Enfim, são estes sinais de um novo tempo e da possibilidade de novas relações entre os índios, os pesquisadores e os museus etnográficos

O momento atual revela-se favorável à re-contextualização destas coleções, seja por meio do estudo do processo que as originou, por parte dos etnólogos interessados em estudar a história da antropologia no Brasil, seja por meio dos grupos indígenas interessados não apenas em resgatar e re-significar os testemunhos históricos de suas produções materiais guardadas em museus de dentro e fora do país, como também em testar a operacionalidade da instituição museu em seu próprio meio.
As demandas indígenas e os processos de apropriação da instituição museu, por parte dos povos indígenas, revelam um processo no qual as coleções etnográficas tornaram-se alvo de um interesse renovado e ampliado por parte destes atores. Hoje, cada vez mais, as comunidades indígenas não se relacionam mais com os etnólogos e os museus na posição de meras fontes produtoras de artefatos, mas se dirigem a ambos enquanto "herdeiras" ou "parte interessada" nos testemunhos da produção material de seus antepassados. Algumas experiências em curso apontam para um re-equacionamento das relações no interior deste campo, tal como evidenciam as iniciativas recentes de criação de museus e centros de expressão cultural pelos próprios índios, que têm contado com pouca colaboração dos museus etnográficos e mesmo das universidades.

Pensar na possibilidade de estabelecimento de novas relações entre índios, pesquisadores e museus implica em reconhecer, citando aqui o professor Ulpiano Bezerra de Menezes, que os objetos indígenas são ao mesmo tempo produtos e vetores de relações sociais. Ao serem musealizados, por meio do processo de coleta e guarda em museus etnográficos, tais objetos deixam de ser produtos de relações sociais precisas, entre indivíduos e grupos, para servirem de exemplares da produção material deste ou daquele povo.

É enquanto produtos de relações sociais que os objetos indígenas são coletados, guardados em reservas técnicas e apresentados em exposições, principalmente as etnográficas. Talvez o que falte experimentar seja encará-los como vetores de novas possibilidades de relações, envolvendo as próprias comunidades indígenas em ações de difusão de suas produções materiais. Para isso, o primeiro passo seria restituir valor social aos objetos coletados e guardados. Hoje, objetos etnográficos depositados em museus são considerados como patrimônio da nação, por isso precisam ser conservados, porque são testemunhos de formas de vida particulares que revelam ou que expressam evidências do nosso passado, do passado dos povos indígenas com os quais se erigiu a nação. Quando os objetos indígenas são incorporados no museu, não só 
se produz um "apagamento patrimonial específico" vinculando esses objetos a este ou aquele povo, como se cria um novo vínculo de pertencimento: eles passam a ser patrimônio indígena e com isso, como nos provoca Lucia Hussak, "patrimônio de uma outra cultura, a nossa" (Hussak, 2005: 72).

Os povos indígenas, porém, estão atuantes no cenário nacional, não se constituindo apenas em evidência do nosso passado, mas são partícipes do presente e é preciso pensar e encontrar um lugar para eles no futuro. É esse o sentido imposto pela Constituição de 1988 , ao abandonar a tradição legislativa e jurídica da necessidade imperiosa da integração e da assimilação dos índios à comunidade nacional, impondo um novo paradigma, alicerçado na idéia de que os índios têm direito a manutenção de suas identidades, de seus modos de vida, de suas formas de ver e de estar nesse mundo, cabendo ao Estado não mais buscar sua transição para um outro estágio ou etapa de evolução, mas garantir condições dignas para sua sobrevivência e para um convívio equilibrado com os demais segmentos da sociedade nacional.

Assim, os objetos guardados em museus não são apenas "patrimônio da nação", eles são patrimônios de povos específicos, produzidos por pessoas, cujos descendentes ainda estão vivos e para os quais essas produções poderiam ter novos e insuspeitados sentidos. É na condição de patrimônios étnicos que eles podem ser postos à disposição desses povos indígenas e é com este status que eles interessam a estes povos. Pensar na possibilidade da gestão compartilhada destes acervos, envolvendo representantes das comunidades indígenas e museus guardiães pode abrir novas possibilidades de diálogo e cooperação neste campo de relações.

Registre-se, aqui, o exemplo do Museu do Índio, no Rio de Janeiro, que tem ensaiado passos neste sentido com suas exposições de longa duração, envolvendo representantes indígenas tanto na produção e preparação dos objetos quanto na discussão da proposta da exposição a eles dedicada. Foi este o caminho percorrido numa exposição sobre os Wajãpi e sobre os povos indígenas do Oiapoque apresentadas nos últimos anos naquela instituição. $\mathrm{O}$ caráter inovador das propostas conceituais e museológicas destas duas exposições apontam para o surgimento de novas possibilidades de práticas museológicas, ancoradas em novas formas de relacionamento entre os índios, os pesquisadores e os museus etnográficos que guardam evidências e registros de suas produções materiais.

Rompendo com o paradigma do patrimônio da nação, iniciativas como estas evidenciam a possibilidade de estabelecimento de outros tipos de relações de comunicação e de informação, contribuindo para a formação de uma nova visão sobre os povos indígenas a partir de uma popularização de conhecimentos antropológicos. Informadas por pesquisas de ponta e por publicações recentes, levam ao grande público questões novas a respeito da existência desses povos e de sua persistente presença no cenário nacional.

Se historicamente o campo de relações entre índios, pesquisadores e museus se estruturou a partir de uma posição marginal dos índios, hoje o que se verifica é um protagonismo crescente destes atores, não só exigindo novas formas de relacionamento, como colocando em pauta novos desafios.

Da posição subalterna no campo de relações, os índios passaram a sujeitos ativos, produtores de demandas e produtos culturais diversificados. Uma nova imagem sobre as culturas indígenas vem sendo construída nos últimos anos, e demandam dos antropólogos e dos museus etnográficos novos posicionamentos. $\mathrm{O}$ que estou querendo chamar atenção, para finalizar, é que se no começo do século passado os museus etnográficos e os antropólogos tinham o monopólio sobre o discurso a respeito das sociedades indígenas, hoje ele não mais existe. Nesse novo momento deste campo de relações, tanto os antropólogos quanto os museus etnográficos têm não só que dialogar com os discursos e com os produtos culturais elaborados pelos próprios índios e por outros agentes culturais que se especializaram na difusão da "cultura indígena" como tem que levar sua reflexão a estes novos interlocutores. Cada vez mais somos instados a justificar nossas práticas de pesquisa e a tomar os representantes das sociedades que estudamos como interlocutores, num processo de negociação que se torna complexo a cada dia. 


\section{Bibliografia:}

APADURAI, ARJUN. The Social life of things: commodities in cultural perspectives, Cambridge University Press, Cambridge. 1986.

AZEVEDO, FERNANDO. "A Antropologia e a Sociologia no Brasil" in As Ciências no Brasil, vol. II, Ed. Melhoramentos, São Paulo, págs. 353-399. 1957.

BARTH, FREDERICK. Ethnic Groups and Boundaries - The social organization of cultural diferences, Little Brown Co., Boston. 1969.

BOURDIEU, PIERRE. "O Campo Científico" in ORTIZ, RENATO Pierre Bourdieu, Ed. Ática, São Paulo, págs. 122-125. 1982.

CARDOSO DE OLIVEIRA, ROBERTO. Sobre $o$ Pensamento Antropológico, Tempo Brasileiro/CNPq, Rio de Janeiro/Brasilia, págs. 13-25 e 109-128. 1988.

CARNEIRO DA CUNHA, MANUELA (Org.) - História dos Índios no Brasil, Cia. das Letras/Fapesp/ SMC-SP, São Paulo, 611 págs.

CLIFFORD, JAMES. "Objects and Selves: An Afterword"in STOCKING, GEORGE (Org.) $O b$ jects and Others Essays on museums and material culture, History of Anthropology, vol. 3, The University of Wisconsin Press, Wisconsin. 1985.

The Predicament of Culture Twentieth Century Ethnography, Literature and Art, Harvard University Press, Mass. 1988.

"Muséologie et contre-histoires. Voyages sur la Côte Nord-Ouest" in Gradhiva, 11, Paris, págs. 81-101. 1992.

Routes, travel and translation in the late twentieh century, Harvard University Press, Boston. 1997.

CORRÊA, MARIZA. "Traficantes do Excêntrico Os antropólogos no Brasil dos anos 30 aos anos 60" in Revista Brasileira de Ciências Sociais, n.6, vol.3, ANPOCS, Rio de Janeiro, págs. 79-98. 1988.

"Traficantes do Simbólico" in História da Antropologia no Brasil (1930-1960 Testemunhos: Emilio Willems Donald Pierson, Vértice/ Editora da UNICAMP, págs. 13-26. 1987.

DAMY, ANTONIO SERGIO e HARTMANN, THEKLA. "As coleções etnográficas do Museu Paulista: composição e história" in Revista do Museu Paulista, N.S., vol. XXXI, USP, São Paulo, págs. 220-272. 1986.
DORTA, SONIA FERRARO - "Coleções etnográficas: 1650-1955" in CARNEIRO DA CUNHA, MANUELA (Org.) - História dos Índios no Brasil, Cia. das Letras/Fapesp/SMC-SP, São Paulo, págs.501-528.

FENTON, W. "The advancement of material culture studies in modern anthropological research" in RICHARDSON, M (Ed.) - The Human Mirror, Louisiana University Press, Louisiana, págs. 15-36. 1974.

FERNANDES-DIAS, JOSÉ ANTONIO B. Recensões: Le Musée d'Ethnographie du Trocadéro (18781908) Anthropologie et Muséologie en France" in Antropologia Portuguesa, Vol.9-10, Coimbra, págs. 195-205. 1991.

Memorandum a acompanhar a carta da Coiab ao senhor Presidente da República, Lisboa, manuscrito, 40 págs. 1998.

FARIA, LUIZ DE CASTRO. "A Antropologia no Brasil. Depoimento sem compromissos de um militante em recesso" in Anuário Antropológico 82, Tempo Brasileiro/Universidade Federal do Ceará, págs. 228-250. 1984.

Antropologia, Espetáculo e Excelência, Tempo Brasileiro, Rio de Janeiro, 105 págs. 1993.

FREIRE, JOSÉ RIBAMAR BESSA. "A descoberta do Museu pelos Índios" in Cadernos de Etnomuseologia - Os Índios e o Museu, N. 01, Programa de Estudos dos Povos Indígenas/UERJ, Rio de Janeiro, págs.9-36. 1998.

FUNAI. Documento final da $1^{a}$. Conferência Nacional dos Povos Indígenas, Funai, Brasília, mimeo., 58 págs. 2006.

GALLOIS, DOMINIQUE T. "O acervo etnográfico como centro de comunicaçāo intercultural" in $\mathrm{Ci}$ ência em Museus, MPEG/CNPq, vol. 1, n.2, Belém, págs. 137-142. 1989

GEERTZ, CLIFFORD. El Antropologo como autor, Paidos Studio, Barcelona, págs.35-58. 1989.

GONÇALVES, JOSÉ REGINALDO SANTOS. "O templo e o fórum: reflexões sobre museus, antropologia e cultura" in CHUVA, MÁRCIA (org.) $A$ invenção do Patrimônio continuidade e ruptura na constituição de uma política oficial de preservação no Brasil, MINC/IPHAN, págs. 27 - 40. 1995.

GRABURN, NELSON. Ethnic and Tourist arts Cultural expressions from the fourth world, University of California Press, Berkeley. 1976.

GRUBER, JACOB. "In Search of Experience" in Helm, June (ed.) Pioneers of American Anthropologist The uses of biography, University of Washington Press, Seattle. 1966. 
GRUBER, JUSSARA. "Museu Magüta" in Piracema - Revista de Arte e Cultura, IBAC, Rio de Janeiro, págs. 84-94. 1994.

GRUPIONI, LUÍS DONISETE BENZI. "Levantamento de Coleções Bororo em Museus Brasileiros" in Ciência em Museus, MPEG/CNPq, vol. 1, n.2, Belém, págs. 123-136. 1989.

Levantamento de coleções etnográficas de Curt Nimuendajú em museus brasileiros, manus., PPGAS/USP, São Paulo, 158 págs. 1995.

Coleções e Expedições Vigiadas: os etnólogos no Conselho de Fiscalização das Expedições Artísticas e Científicas no Brasil, Ucitec/Anpocs, São Paulo. 1998.

HARTMANN, GUNTER. "Las Colecciones de pueblos indígenas de Sudamérica en el Museo Etnológico de Belín" in Scripta Ethnologica, Vol. VII, Buenos Aires, págs. 23 - 32. 1983.

HANDLER, RICHARD. "On Having a Culture: Nationalism and the Preservation of Quebec's Patrimoine" - in Stocking, George W (ed.) Objects and Others Essays on Museums and Material Culture, The University of Wiscosin Press, Wiscosin, págs: 192-217. 1985.

HERKOVITS, MELVILLE J. "A genealogy of Ethnological Theory" in Spiro, Melford E. (Ed.) Context and Meaning in Cultural Anthropology, The Free Press New York, págs. 403-415. 1965.

KÄSTNER, KLAUS-PETER. "As coleções brasileiras do Museu Estatal de Etnologia de Dresden" in $R \boldsymbol{R}$ vista do Museu de Arqueologia e Etnologia, USP, São Paulo, n. 01, págs. 147 164. 1991.

KUPER, ADAM. Antropólogos e Antropologia, Francisco Alves, Rio de Janeiro, 228 págs. 1978.

LÉVIS-STRAUSS, CLAUDE. "Em prol de um Instituto de Antropologia Física e Cultural" in Revista do Arquivo Municipal, XVIII, São Paulo. 1935.

Tristes Trópicos, Edições 70, Lisboa, 415 págs. 1986 (1955).

. Saudades do Brasil, Companhia das Letras, São Paulo, 227 págs. 1994.

Saudades de São Paulo, Companhia das Letras, São Paulo, 107 págs. 1996.

LÉVIS-STRAUSS, CLAUDE e ERIBON, DIDIE. De Perto e de Longe, Editora Nova Fronteira, Rio de Janeiro, 235 págs. 1990 (1988).

LIMA, ANTONIO CARLOS DE SOUZA. "Os Museus de História Natural e a Construção do Indigenismo: nota para uma sociologia das relações entre campo intelectual e campo político no Brasil" in $\mathrm{Co}$ municação, n. 13, PPGAS/Museu Nacional/UFRJ, Rio de Janeiro, 85 págs. 1989.

Um Grande Cerco de Paz Poder tutelar, indianidade e formação do Estado no Brasil, Vozes, Petrópolis, 335 págs. 1995.

LOWIE, ROBERT H. "Erland Nordenskiöld" in American Anthropologist, N. S., Vol. 35, págs.158164. 1933.

"Field work in Absentia" in - Robert H. Lowie Ethnologist - A Personal Record, University of California Press, Berkely, págs. 119-126. 1959.

LURIE, N. "Museumland revisited" in Human Org, Vol.40, págs.180-187. 1981.

GEORGE, MARCUS e FISCHER, MICHAEL M. J. Anthropology as Cultural Critique - na experimental movent in the Human Sciences, The University of Chicago Press, Chicago. 1986.

MENESES, Ulpiano Toledo Bezerra de. "A cultura material no estudo das sociedades antigas" In: Revista de História, São Paulo, USP, n. 115, p. 103-117. 1985.

MÉTRAUX, ALFRED. "El Museo Etnografico de Gotemburgo" in Revista Geográfica Americana, 3(19), Buenos Aires, abril de págs. 253 - 256. 1935.

MICELI, SÉRGIO. Intelectuais e Classe Dirigente no Brasil (1920-1945), Difel, SP/RJ, 210 págs. 1979.

MUSEU DE ASTRONOMIA E CIÊNCIAS AFINS. Arquivo do Conselho de Fiscalização das Expedições Artísticas e Científicas no Brasil Inventário Analítico, MAST, Rio de Janeiro, 285 págs. 1988.

MUSEU DO ESTADO DE PERNAMBUCO. Exposição de peças arqueológicas e etnogräficas coleção Carlos Estevão, catálogo de exposição, Recife, 20 págs. 1980.

MUSEUM NATIONAL D'HISTOIRE NATURELLE. "A L'occasion de l'exposition 'Les Amériques de Claude Lévi-Strauss'" in Le Petit Journal du Musée de l'Homme, Paris, 8 págs. 1989.

NIMUENDAJÚ, CURT. The Eastern Timbira - Traduzido e Editado por Robert H. Lowie, University of California Publications in American Archaeology and Ethnology, vol. 41, Berkeley e Los Angeles, x, 357 págs. 1946.

"Os Apinayé" in Boletim do Museu Paraense Emílio Goeldi, XII, Belém, 146 págs. 1956.

Mapa Etno-histórico de Curt Nimuendajú, Fundação IBGE / Fundação Nacional Pró-Memória, Rio de Janeiro. 1981. 
OLIVEIRA FILHO, JOÃO PACHECO DE. "A viagem da volta: reelaboração cultural e horizonte político dos povos indígenas no nordeste" in Atlas das Terras Indígenas do Nordeste, Peti/Museu Nacional, Rio de Janeiro, págs.v-viii. 1993.

RAMOS, ALCIDA RITA. "Ethnology Brazilian Style" in Série Antropologia, n.89, Brasília, 38 págs. 1990.

RIBEIRO, BERTA. "Museu: veículo comunicador e pedagógico" in Revista Brasileira de Estudos Pedagógicos, Vol. 66, n. 152, INEP/MEC, págs.77-99. 1985.

"Os estudos de cultura material: propósitos e métodos" in Revista do Museu Paulista, Vol 30, USP, São Paulo, págs. 13-41. 1986.

"Museu e memória: reflexões sobre o colecionamento" in Ciência em Museus, MPEG/CNPq, vol. 1, n.2, Belém, págs. 109-122. 1989.

RIBEIRO, BERTA \& VAN VELTHEM, LUCIA H. "Coleções etnográficas: documentos materiais para a história indígena e a etnologia" in Manuela Carneiro da Cunha (Org.) - História dos Índios no Brasil, Fapesp/SMC/Companhia das Letras, São Paulo, págs. 103-112. 1992.

RIBEIRO, DARCY. A Política Indigenista Brasilei$r a$, Mininstério da Agricultura/Serviço de Informação Agrícola, Rio de Janeiro, 178 págs. 1962.

RODRIGUES, IVELISE e FIGUEIREDO, NAPOLEÃO. Catálogo das coleções etnográficas do Museu Paraense Emílio Goeldi e Universidade Federal do Pará, MPEG, Belém, 35 págs. 1982.

ROTHSCHILD, NAN A. e CANTWELL, ANNEMARIE. The research potencial of Anthropological Museum Collections, Annals New York Academy of Sciences, New York. 1981.

RUBINO, SILVANA. As Fachadas da História: os antecedentes, a criação e os trabalhos do Serviço do Patrimônio Histórico e Artístico Nacional, 19371965, Dissertação de Mestrado, Unicamp, Campinas, 206 págs. 1991.

SCHUMANN, LEONOR e HARTMANN, TEKLA. "Coleções etnográficas brasileiras em Stuttgart: his- tórico e composição" in Revista do Museu de Arqueologia e Etnologia, n. 02, USP, São Paulo, págs. 125 a 132.1992.

SCHWARCZ, LILIA. Os guardiões de nossa historia oficial, Textos n.9, IDESP, São Paulo, 79 págs. 1989.

"O Nascimento dos Museus Brasileiros (1870-1910)" in MICELI, SÉRGIO (org) - História das Ciências Sociais no Brasil, Vol. 1, Vértice/Finep/ Idesp, São Paulo, págs. 20 a 71. 1989.

STOCKING, GEORGE W. "Essays on Museums and Material Culture" in (edit.) - Objects and Others Essays on museums and material culture, History of Anthropology, vol. 3, The University of Wisconsin Press, Wisconsin, págs. 03-14. 1985.

STURTEVANT, WILLIAM C. Guide to Field Collecting of Ethnographic Specimens, Smithsonian Institution, Washington, 41 págs. 1969.

SUANO, MARLENE. O que é Museu, Editora Brasiliense, São Paulo, 101 págs. 1986.

TAYLOR, ANNE-CHRISTINE. "L'Americanisme Tropical, une frontiere fossile de L Ethnologie?" in RUPP-EISENREICH, BRITTA (Org) Histoires de l'Anthropologie: XVI-XIX Siècles, Klinksieck, Paris, págs. 213-233. 1984.

VAN VELTHEM, LUCIA HUSSAK. "A arte de colecionar: introdução museográfica" in A pele de Tulupere: estudo dos trançados Wayana-Aparai, Dissertação de Mestrado, manus., USP, págs.13-64. 1984.

"Objeto etnográfico, coleções e museus" In MOREIRA, E. et alli (Org.) Propriedade Intelectual e Patrimônio Cultural: proteção do conhecimento e das expressões culturais tradicionais, Anais, CESUPA/MPEG, Belém, págs. 71-77. 2005.

von IHERING, HERMANN. "O Museu Paulista nos anos de 1906 a 1909" in Revista do Museu Paulista, Vol VIII, São Paulo, págs. 1-22. 1911.

"O Museu Paulista nos anos de 1910, 1911 e 1912" in Revista do Museu Paulista, Vol IX, São Paulo, págs. 5-24. 1914. 